\title{
PULSED LASER EVAPORATION AND EPITAXY
}

\author{
J.J. DubowskI \\ Institute for Microstructural Sciences, National Research Council Canada \\ Ottawa, Ontario, K1A 0R6, Canada
}

\begin{abstract}
The application of pulsed lasers for vaporization (ablation) of solid targets appears to be the most natural way to produce high purity fluxes of atoms/ions suitable for epitaxial growth of thin films. Since the early 1960's this unique approach has been the subject of steadily growing interest in the deposition of metals, dielectrics, semiconductors and since 1987, high- $T_{c}$ superconductors. Laser induced target surface morphology changes, properties of laser induced vapours and pulsed deposition rate associated with the use of a pulsed laser for vacuum epitaxy are discussed. A pulsed laser evaporation and epitaxy (PLEE) system is described and the results of PLEE application for the growth of $\mathrm{Cd}_{1-x} \mathrm{Mn}_{x} \mathrm{Te}$ and $\mathrm{CdTe}-\mathrm{Cd}_{1-x} \mathrm{Mn}_{x} \mathrm{Te}$ quantum well and superlattice structures are reviewed. Feasibility of PLEE in bandgap engineering is also discussed.
\end{abstract}

PACS numbers: $68.55:-\mathrm{a}, 78.65$. Fa

\section{Introduction}

Advantages of the use of lasers as a heat source for vacuum vaporization of solid targets and deposition of thin films, especially those of pulsed lasers, have been long recognized [1]. Laser induced congruent vaporization gives the possibility of deposition of multi-element materials from single targets, which is an attractive feature in thin film deposition. Early experiments with pulsed lasers were carried out for the deposition of metals, dielectrics and semiconductors. Since 1986, the interest in this method has been strongly stimulated by its usefulness in the deposition of high- $\mathrm{T}_{\mathrm{c}}$ superconductors. Progressively, as laser characteristics and performance were improved, better control over the deposition process was developed. Significant progress and a steady increase in the interest of deposition by pulsed lasers has been observed, especially during the last decade. Several names have been used to describe this process: pulsed laser deposition, pulsed laser evaporation and epitaxy (PLEE) [2], laser-molecular beam epitaxy (MBE) [3] and laser ablation [4]. It has been claimed that the quality of laser-grown structures can be 
comparable or even better than that of structures grown today with state-of-the-art techniques such as MBE or metal-organic chemical vapour deposition (MOCVD). The first observation of the quantum Hall effect in $\mathrm{HgTe}-\mathrm{HgCdTe}$ superlattices has been recorded in a laser-MBE grown system [3]; the first observations of high order $(n=8)$ outgoing resonance Raman spectra for $\mathrm{Cd}_{1-x} \mathrm{Mn}_{x}$ Te have been recorded for PLEE grown material [5] and quantum confinement has been observed in PLEE $\mathrm{CdTe}-\mathrm{Cd}_{0.90} \mathrm{Mn}_{0.10} \mathrm{Te}$ quantum well structures [6].

The potential advantages in the use of PLEE include:

1. An ability to carry out vaporization of any solid or liquid target.

2. A pure high vacuum environment where only a small part of a vaporized target is at an elevated temperature.

3. Congruent vaporization of multi-element targets.

4. Deposition in a 'pulse-by-pulse' mode which provides better control of thickness.

5. Laser induced vapours may contain atomic and/or low-meric species, $\mathrm{As}_{2}$ or Te for example, which contrasts with a simple thermal vaporization process.

6. Energy of atoms/ions which constitute laser induced vapours may be from several $\mathrm{eV}$ to hundreds of $\mathrm{eV}$. This may result in increased mobility of atoms arriving at the substrate surface and may lead to low-temperature epitaxy.

7. Compatibility with reactive deposition as a consequence of the absence of heating devices operating at temperatures higher than that of the substrate in the PLEE chamber.

Some features of laser deposition like 'pulse-growth-rate' which offers thickness control to better than $0.5 \AA /$ pulse is difficult to be matched by any other conventional deposition technique. An ability for instantaneous mixing of material fluxes generated by laser ablation of different targets is another attractive feature of vacuum pulsed laser deposition which could be applied, for instance, in bandgap engineering.

In this paper we provide a short review on PLEE. We will illustrate the unique PLEE features with results that mostly concern $\mathrm{CdTe}$ and $\mathrm{Cd}_{1-x} \mathrm{Mn}_{x} \mathrm{Te}$ thin films. The paper by no means pretends to be an exhaustive review of current results of the application of pulsed laser evaporation for deposition of thin films and we refer a more interested reader to several papers which have been published recently $[2-4,7]$.

\section{Pulsed laser evaporation and epitaxy system}

A schematic diagram of the PLEE system is shown in Fig. 1. It consists of a growth chamber and a load-lock for introducing substrates and targets. A cryopump is used to generate a vacuum in the growth chamber (base pressure 


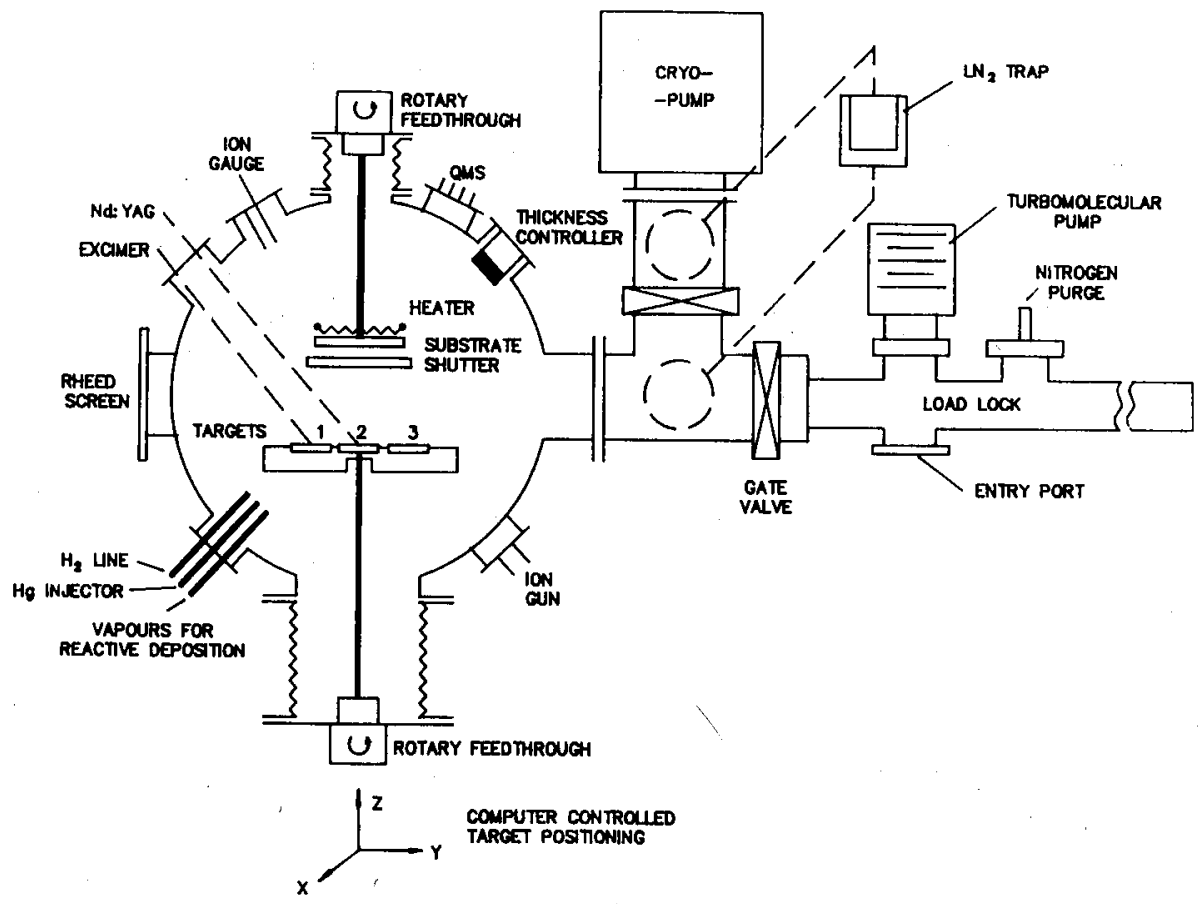

Fig. 1. Schematic diagram of the PLEE system.

after bakeout $\sim 1.5 \times 10^{-10}$ Torr), and a turbomolecular pump backed with a rotary pump is applied to evacuate the load-lock volume. A nitrogen purge is always used when the entry port is open, which reduce water vapour contamination and the time required for load-lock evacuation. The growth chamber is equipped with a substrate heater $\left(25-900^{\circ} \mathrm{C}\right)$, saddle ion gun used for substrate surface cleaning, quadrupole mass spectrometer, quartz crystal monitor, ion gauge and a reflection high-energy electron diffraction system with a $30-\mathrm{kV}$ electron gun supply. Substrates are mounted on a Mo block that is rotated during deposition to minimize the lateral temperature gradient and film thickness nonuniformity. This block can be electrically isolated in order to carry out deposition in the presence of an electric field applied between the target and the substrate. A target susceptor holds three targets of $11 \times 11 \times 6 \mathrm{~mm}$ each mounted on a Mo holder. Targets can be continuously rotated and their position is computer controlled with a motorized X-Y-Z stage. Targets are ablated with neodymium-doped yttrium aluminum garnet ( $\mathrm{Nd}: \mathrm{YAG}$ ) and excimer $\mathrm{XeCl}$ lasers. The laser characteristics are given in Table I.

Precise regulation of the laser power output, number of laser pulses, and switching between targets have been carried out with a microprocessor controller interfaced to a computer. Figure 2 shows schematically the PLEE coordination and regulatory system [8]. It consists of a control computer with a triggered $\mathrm{Si}$ 


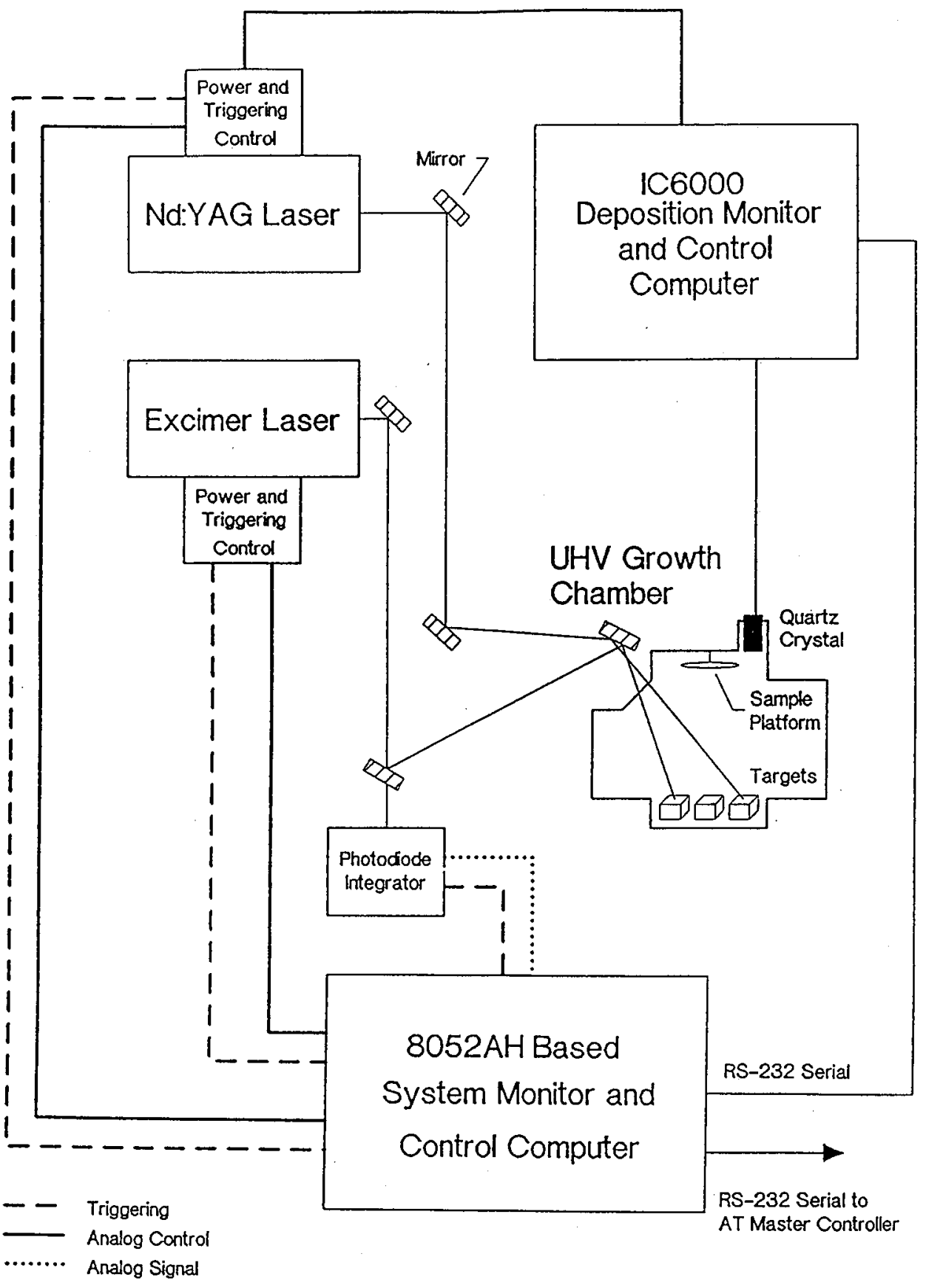

Fig. 2. Outline of the laser coordination and regulatory system [8]. 
photodiode integrator unit to monitor the excimer laser pulse energy and a deposition monitor/control computer (Inficon IC-6000) with feedback to the Nd:YAG laser power supply. The control of deposition rates and thicknesses of individual layers is carried out with an IBM AT compatible computer. This system allows fast laser switching between ablated targets without the need of mechanical shutters, thus providing a high degree of control of the layer thicknesses.

\section{TABLE I}

Characteristics of the lasers used in PLEE.

\begin{tabular}{c|c|c|c|c|c}
\hline \hline Laser & $\begin{array}{c}\text { Wavelength } \\
(\mu \mathrm{m})\end{array}$ & $\begin{array}{c}\text { Pulse } \\
\text { duration } \\
(\mathrm{ns})\end{array}$ & $\begin{array}{c}\text { Repetition } \\
\text { rate } \\
(\mathrm{Hz})\end{array}$ & $\begin{array}{c}\text { Pulse peak } \\
\text { power } \\
\left(\mathrm{W} / \mathrm{cm}^{2}\right)\end{array}$ & $\begin{array}{c}\text { Spot size } \\
(\mathrm{mm})\end{array}$ \\
\hline $\mathrm{Nd}: \mathrm{YAG}$ & 1.06 & 90 & $\leq 2 \times 10^{4}$ & $10^{6}-10^{8}$ & $0.2-0.3$ \\
$\mathrm{XeCl}$ & 0.308 & 30 & $\leq 80$ & $10^{6}-10^{8}$ & $0.5-5.0$
\end{tabular}

Epitaxial growth of CdTe films was carried out by ablation of a single $\mathrm{CdTe}$ target, whereas growth of the ternary $\mathrm{Cd}_{1-x} \mathrm{Mn}_{x} \mathrm{Te}$ films was carried out either by simultaneous ablation of $\mathrm{Cd}_{1-x} \mathrm{Mn}_{x} \mathrm{Te}$ and $\mathrm{Cd}$ targets $[9,10]$ or from a $\mathrm{Cd}_{1-x} \mathrm{Mn}_{x}$ Te alone [11]. We were able to generate a flux of $\mathrm{Cd}$ atoms from a Nd:YAG ablated Cd target, up to about $10^{17}$ atoms $/\left(\mathrm{cm}^{2} \mathrm{~s}\right)$. In this way it was possible to reproduce with high accuracy the chemical composition $x$ of the ablated target in the PLEE films. The Mn concentration in $\mathrm{Cd}_{1-x} \mathrm{Mn}_{x}$ Te films which were obtained without an additional flux of Cd was higher than that of the ablated target and was substrate temperature dependent. For example, ablation of a $\mathrm{Cd}_{0.93} \mathrm{Mn}_{0.07} \mathrm{Te}$ target resulted in a series of $\mathrm{Cd}_{1-x} \mathrm{Mn}_{x} \mathrm{Te}$ films with $x$ increasing from 0.096 to 0.112 when substrate temperature was increased from 200 to $240^{\circ} \mathrm{C}$. These results are summarized in Table II.

TABLE II

Properties of PLEE (111) $\mathrm{Cd}_{1-x} \mathrm{Mn}_{x} \mathrm{Te}$ layers grown on (111)GaAs substrates with additional flux of Cd [10].

\begin{tabular}{c|c|c|c|c}
\hline \hline & & & \multicolumn{2}{|c}{$x$} \\
\cline { 4 - 5 } Sample & $T_{\mathbf{s}}\left({ }^{\circ} \mathrm{C}\right)$ & $d(\mu \mathrm{m})$ & EDAX & PL \\
\hline Target & - & - & 0.073 & 0.079 \\
CMT-301 & 310 & 1.9 & 0.087 & 0.092 \\
CMT-300 & 290 & 2.0 & 0.089 & 0.095 \\
CMT-303 & 290 & 0.8 & 0.075 & 0.078 \\
CMT-306 & 290 & 1.8 & 0.080 & 0.079 \\
CMT-304 & 270 & 0.7 & 0.083 & 0.080 \\
CMT-305 & 270 & 1.0 & 0.079 & 0.082 \\
CMT-308 & 270 & 1.5 & 0.079 & 0.076 \\
CMT-309 & 270 & 2.6 & 0.080 & 0.076
\end{tabular}




\section{Diagnostics of the laser induced target changes and laser induced vapours}

\subsection{Threshold for ablation}

Vaporization characteristics of a specific target with a single laser pulse is dependent both on the physical properties of the target material such as melting temperature, thermal diffusivity, optical reflectivity, and surface roughness, and the laser parameters such as photon wavelength, peak pulse energy $E_{\mathrm{p}}$, and pulse duration $\tau$. As an example, vaporization of Si with $7 \mathrm{~ns}$ pulses of an Nd:YAG laser operating at $\lambda=0.532 \mu \mathrm{m}$ is achieved [12] for $E_{\mathrm{p}} \sim 1 \mathrm{~J} / \mathrm{cm}^{2}$. However, we have found that weak absorption of $\mathrm{Si}$ at $1.06 \mu \mathrm{m}$ and its high diffusivity coefficient prevent $\mathrm{Si}$ from being efficiently vaporized with $90 \mathrm{~ns}$ pulses of the Nd:YAG laser operating at $1.06 \mu \mathrm{m}$ for $E_{\mathrm{p}}$ up to $\sim 5 \mathrm{~J} / \mathrm{cm}^{2}$. Under similar experimental conditions an intense vaporization of $\mathrm{CdTe}$ and $\mathrm{Cd}_{1-x} \mathrm{Mn}_{x} \mathrm{Te}$ has been observed [2]. Application of the excimer $\mathrm{XeCl}$ laser leads to efficient vaporization of both $\mathrm{Si}$ and $\mathrm{Cd}_{1-x} \mathrm{Mn}_{x} \mathrm{Te}$ with $E_{\mathrm{p}} \sim 1 \mathrm{~J} / \mathrm{cm}^{2}$. The formation of the plasma in the vicinity of an irradiated spot was associated with ablation of these targets. An illustration of different conditions achieved during laser ablation of the $\mathrm{Si}$ and $\mathrm{Cd}_{1-x} \mathrm{Mn}_{x} \mathrm{Te}$ targets is shown in Fig. 3. Vaporization of Si with a Nd:YAG laser $(\lambda=1.06 \mu \mathrm{m})$
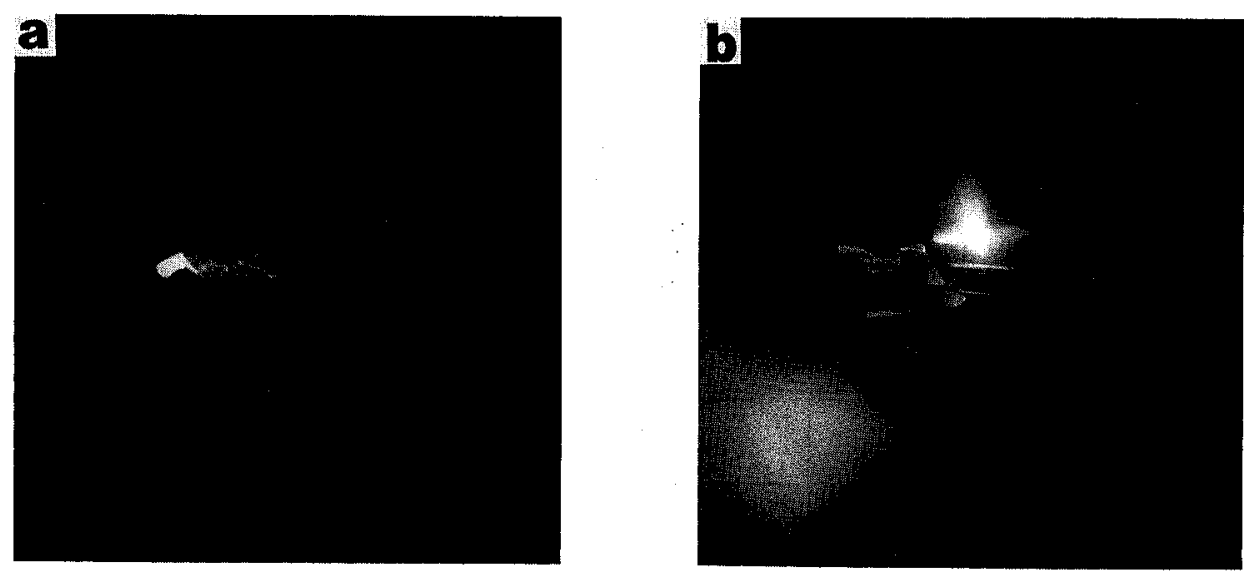

Fig. 3. (a) Nd:YAG laser $\left(\lambda=1.06 \mu \mathrm{m}, \tau=90 \mathrm{~ns}, E_{\mathrm{p}}=5 \mathrm{~J} / \mathrm{cm}^{2}\right)$ induced ablation of $\mathrm{Si}$ and (b) excimer XeCl $\left(\lambda=0.308 \mu \mathrm{m}, \tau=30 \mathrm{~ns}, E_{\mathrm{p}}=5 \mathrm{~J} / \mathrm{cm}^{2}\right)$ induced ablation of $\mathrm{Cd}_{0.93} \mathrm{Mn}_{0.07} \mathrm{Te}$ targets.

is very weak and only a small whitish spot can be seen in the area where the laser beam strikes the target (Fig. 3(a)). In the case of $\mathrm{Cd}_{1-x} \mathrm{Mn}_{x} \mathrm{Te}$ a bright plasma develops near the irradiated spot (Fig. 3(b)). 


\subsection{Surface morphology of the laser ablated target}

Most experimental results with laser ablation of solid targets demonstrate that congruent vaporization takes place and that the chemical composition of the target can be preserved over long vaporization periods. This important feature results from the pulsed ablation characteristic which allows for efficient heat dissipation and for maintaining the target near ambient temperature. An example of laser induced surface morphology of a CdTe target that was developed after irradiation with $1.06 \mu \mathrm{m}$ wavelength photons produced by a Nd:YAG laser [2] is shown in Fig. 4. We would like to point out that CdTe is transparent at this wavelength

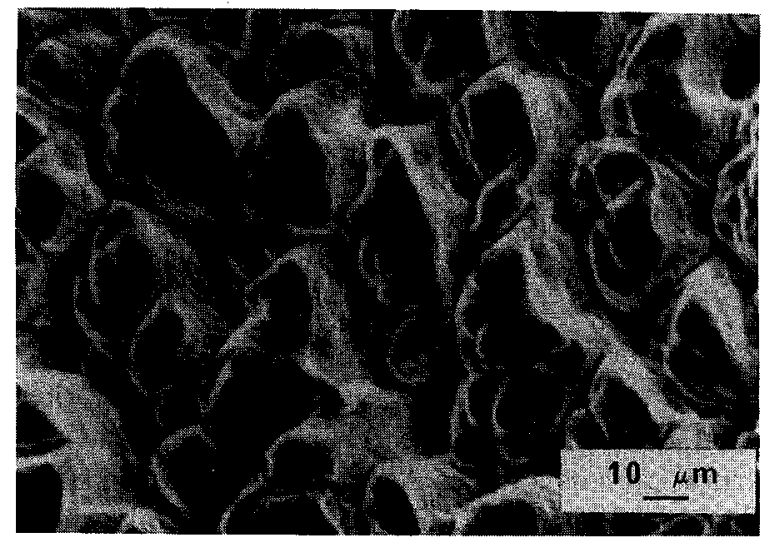

Fig. 4. Surface morphology of a CdTe target ablated with a Nd:YAG laser [2].

and two-photon processes must take place to achieve an efficient absorption and lattice heating by electron-hole plasma recombination. The two-photon absorption takes place at the early stage of ablation until the surface temperature of the target becomes high enough to induce single photon absorption. This process becomes possible at $700^{\circ} \mathrm{C}$ where the energy gap of $\mathrm{CdTe}$ is equal to the photon energy of the Nd:YAG laser. A similar target surface morphology as that shown in Fig. 4 has been observed, for example, in an $\mathrm{YBa}_{2} \mathrm{Cu}_{3} \mathrm{O}_{1-x}$ target vaporized with a $\mathrm{XeCl}$ excimer laser [13].

In some cases, laser ablation may lead to a non-stoichiometric target surface especially when the vapour pressures of the constituent elements of the target are extremely different. Such a situation has been observed following ablation of an InSb target [2]. Figure 5 shows the SEM surface morphology of an InSb target irradiated with pulses from a Nd:YAG laser. Precipitations of In in the form of small balls takes place, most likely due to the extremely low vapour pressure of this element. It is evident that although a tendency towards In deficiency in films grown from such a target could be compensated by an increase of substrate temperature (which would result in lowering the sticking coefficient of $\mathrm{Sb}$ ) the chemical uniformity of InSb films would be difficult to control because the surface stoichiometry of the InSb target would change with time. 


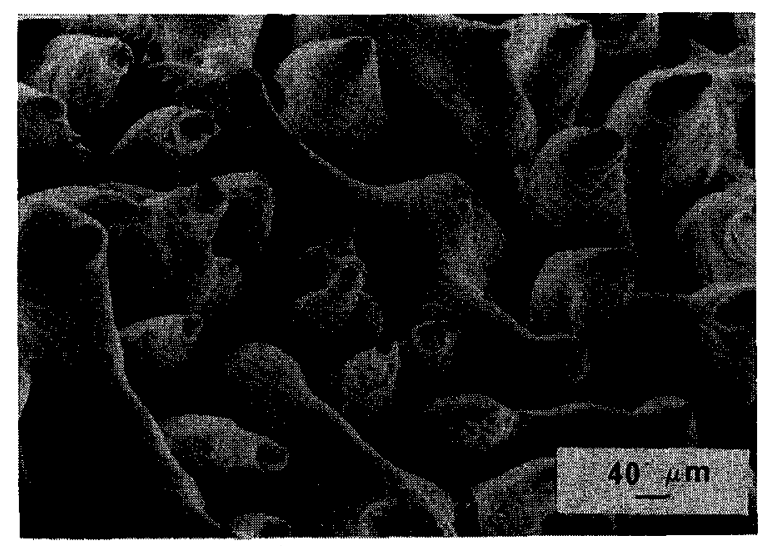

Fig. 5. Surface morphology of a InSb target ablated with a Nd:YAG laser [2].

\subsection{Properties of laser induced vapours}

Depending on the laser pulse peak power and pulse duration applied a flux of vapours leaving the target may contain species that are either typical of pure thermal vaporization, for example $\mathrm{As}_{4}$ and $\mathrm{Te}_{2}$, or species that cannot be obtained with a simple thermal process such as $\mathrm{As}_{2}$ and Te. Ablation of CdTe with $100 \mu \mathrm{s}$ [3] and $90 \mathrm{~ns}$ [14] pulses from Nd:YAG lasers, for example, produces $\mathrm{Cd}$ and Te atoms. Ablation of the same target with $30 \mathrm{~ns}$ pulses of an excimer $\mathrm{KrF}$ laser [15] leads to the formation of $\mathrm{Cd}$ atoms and $\mathrm{Te}_{2}$ molecules. The ability to control the physical properties of laser induced species has been examined during growth of CdTe where it has been demonstrated [3] that the growth kinetics of CdTe on the (111)A face of a CdTe wafer are significantly improved if the deposition is carried out using Te atoms instead of $\mathrm{Te}_{2}$ molecules.

The physical properties of a particle flux produced during laser ablation of a solid target are usually significantly different from those generated in a purely thermal process. The kinetic energy of pulsed laser produced atoms/molecules can reach several hundreds of $\mathrm{eV}$, and the flux can contain neutrals and a significant fraction of ions and electrons. A typical energy distribution of neutrals and ions produced during ablation of a PbTe target with $30 \mathrm{~ns}$ pulses from a Nd:YAG laser [16] is shown in Fig. 6. The contribution from neutrals is described by the low energy portion of this graph with a maximum at $\sim 10 \mathrm{eV}$. The contribution from ions is given by the more energetic portion of this graph with a maximum energy of $\sim 100 \mathrm{eV}$. The most energetic ions have energies exceeding $1 \mathrm{keV}$. A qualitatively similar laser induced flux can be expected for any material, with some differences due to changes in the laser parameters. We have studied [2] the energy and concentration of charged and neutral species produced during vaporization of $\mathrm{CdTe}, \mathrm{CdMnTe}$ and InSb targets with a Nd:YAG laser $(\lambda=1.06 \mu \mathrm{m}, \tau=90 \mathrm{~ns}$, $\left.E_{\mathrm{p}}=0.5-5 \mathrm{~J} / \mathrm{cm}^{2}\right)$. It was found that the maximum mean energy of ions produced was in' the range of $140-450 \mathrm{eV}$. The application of such high-energy ions 


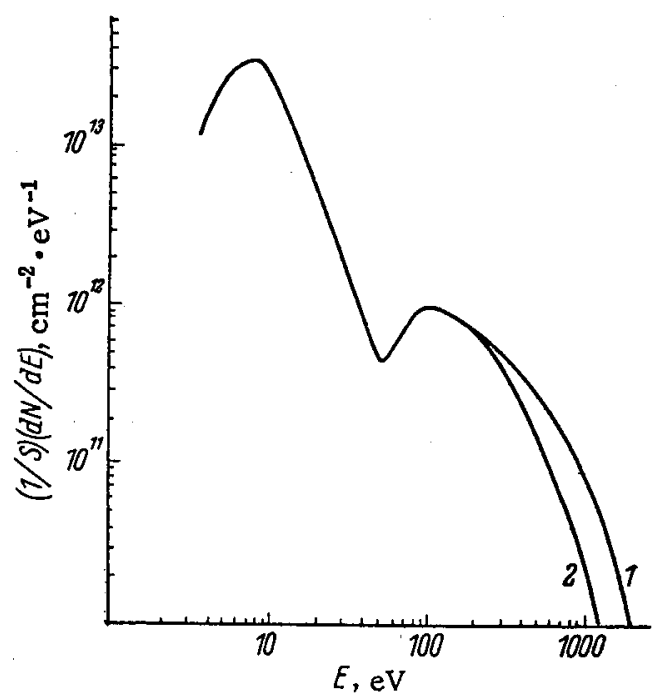

Fig. 6. Energy distribution of neutral particles and ions ejected from $\mathrm{PbTe}$ target with neodymium laser delivering power of $30 \mathrm{~J} / \mathrm{cm}^{2}$ (curve 1) and $12 \mathrm{~J} / \mathrm{cm}^{2}$ (curve 2) [16].

may be useful in the deposition of thin films, assuming that their concentration is well controlled and "splashing" effects can be avoided. Other factors such as target-surface distance, laser pulse duration and spatial overlapping of consecutive pulses on the target surface may also affect the usable range of laser pulse peak power. We have found that the useful laser pulse peak power range for the deposition of $\mathrm{CdTe}$ and $\mathrm{Cd}_{1-x} \mathrm{Mn}_{x}$ Te films with $\mathrm{Nd}$ :YAG and excimer $\mathrm{XeCl}$ lasers was $0.1-1.0 \mathrm{~J} / \mathrm{cm}^{2}$. Incorporation of macroparticles in the grown film, which is associated with high energy laser $\left(E_{\mathrm{p}}>1 \mathrm{~J} / \mathrm{cm}^{2}\right)$ induced ablation, prevented a more systematic study of the influence of energetic native ions on the growth kinetics of CdTe or CdMnTe. The ion/neutral ratio in the laser induced product is also dependent on the pulse peak power and becomes very small with decreasing laser energy, from about 0.30 in the case of PbTe (Fig. 6) to less than 0.05 in the case of CdTe ablated with a Nd:YAG laser operating at $E_{\mathrm{p}}=5 \mathrm{~J} / \mathrm{cm}^{2}[2]$.

\section{Properties of PLEE-grown material}

\subsection{Deposition rate in PLEE}

Due to its pulsed nature, PLEE can be characterized by a pulsed growth rate $R_{p}$ and by a mean growth rate $R_{\mathrm{m}}$ which is calculated from the final thickness of the film and the total time of deposition. Typical growth rates are $R_{\mathrm{p}}=0.02-0.5$ $\AA /$ pulse and $R_{\mathrm{m}}=0.3-5.0 \mu \mathrm{m} / \mathrm{h}$. It is important to note that the presence of impurities on the target surface usually increases the coupling of the laser light to the target. The amount of material ejected with a single laser pulse may therefore 
decrease with number of pulses until clean conditions on the surface are established. Moreover, the geometric changes of the target surface which were discussed above, also significantly modify the vaporization rate. Formation of the surface structure shown in Fig. 4 was accompanied by a decrease of $R_{\mathrm{m}}$ from 4 to $0.8 \mu \mathrm{m} / \mathrm{h}$. This change occurred during the first 500-600 pulses [2].

The uniqueness of PLEE for deposition of thin films results from the fact that while capable of maintaining a relatively high mean growth rate, say 2-5 $\mu \mathrm{m} / \mathrm{h}$, it offers the possibility of thickness increase at a submonolayer level. Thus, the thickness control can be well below the monolayer level. This also allows a precise mixing of different laser induced fluxes which could result in production of structures with their chemical composition arbitrarily changing on the monolayer thickness scale. Such feature is difficult, if not impossible, to be matched by conventional methods of thin film deposition.

Like any other deposition technique, the development of in situ diagnostics of laser induced vapours and the grown material in order to provide feedback for control of the laser parameters and growth conditions will determine further advances in PLEE.

\subsection{Thin films of binary and ternary compounds}

Laser ablation of different targets may lead to the mentioned earlier splashing effects, due either to a direct transport of macroparticles (clusters) from a target to the substrate or by the condensation of energetic particles arriving at the substrate. This problem has been addressed since the early stages of laser application for thin film deposition and different methods have been proposed to avoid this problem. In particular systems with a single reflecting hot screen [17, 18] or two screens [19] have been proposed. There has been a method suggested for the mechanical discrimination of macroparticles [20]. This method is based on the fact that macroparticles travel with significantly lower velocities than most of the laser generated atoms/molecules. A mechanical shutter synchronized with a laser pulse could prevent slowly moving particles from reaching a substrate placed at a distance of a few $\mathrm{cm}$ from the target. Development of different methods for macroparticle discrimination will certainly lead to a better use of high energy atoms/ions produced with high power lasers.

The simplest way of avoiding inclusion of macroparticles in thin films, although not always practical, is to carry out deposition with the minimum laser power required for ablation. In the case of $\mathrm{CdTe}$ we have successfully carried out epitaxial growth using a Nd:YAG laser with $E_{\mathrm{p}} \leq 1 \mathrm{~J} / \mathrm{cm}^{2}$. An example of the surface morphology of PLEE-grown (001) CdTe films on (001) GaAs is shown in Fig. 7 [2]. An initial roughness in the film surface (Fig. 7(a)) is due to the GaAs surface roughness which is typical for chemically etched wafers. As the film thickness progressively increases the surface becomes more uniform and smooth. For a $0.7 \mu \mathrm{m}$ thick film (Fig. 7(c)) a surface with irregularities of $<10 \mathrm{~nm}$ in size is obtained.

High-resolution transmission electron microscopy (HRTEM) investigations of PLEE films grown on different substrates confirmed in situ RHEED observations 

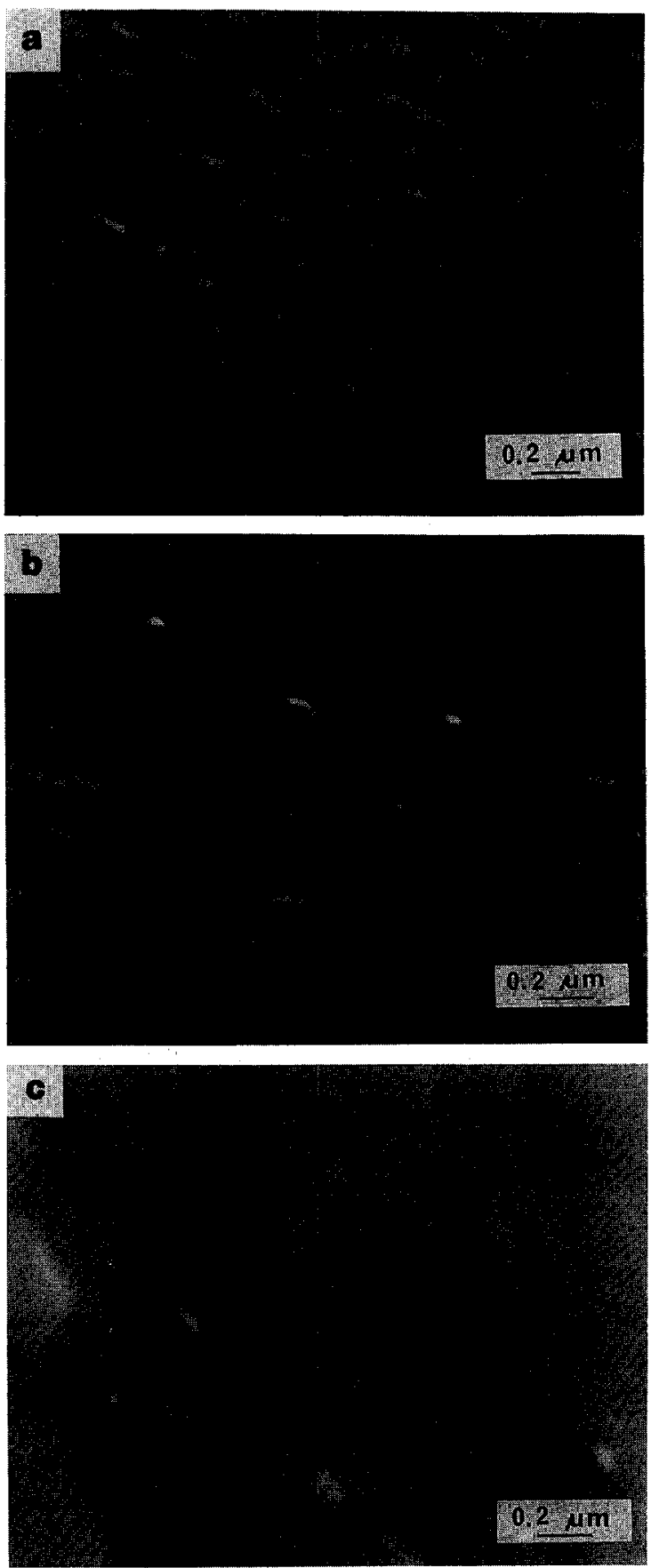

Fig. 7. Surface morphology of PLEE (001) CdTe films (a) $0.09 \mu \mathrm{m}$, (b) $0.39 \mu \mathrm{m}$ and (c) 0.7 $\mu \mathrm{m}$ thick grown on (001) GaAs substrates [2]. 
concerning the orientation of the films and revealed sharp interfaces in most cases. Depending on the substrate preparation procedure [21] both (001) and (111) CdTe films were grown on (001) GaAs substrates. These results are similar to those of MBE grown CdTe samples, e.g. [22], and indicate the feasibility of PLEE in the growth of thin films with controllable crystallographic orientation. An example of a HRTEM (001) CdTe/(001) GaAs cross-section [20] is shown in Fig. 8. Parallel

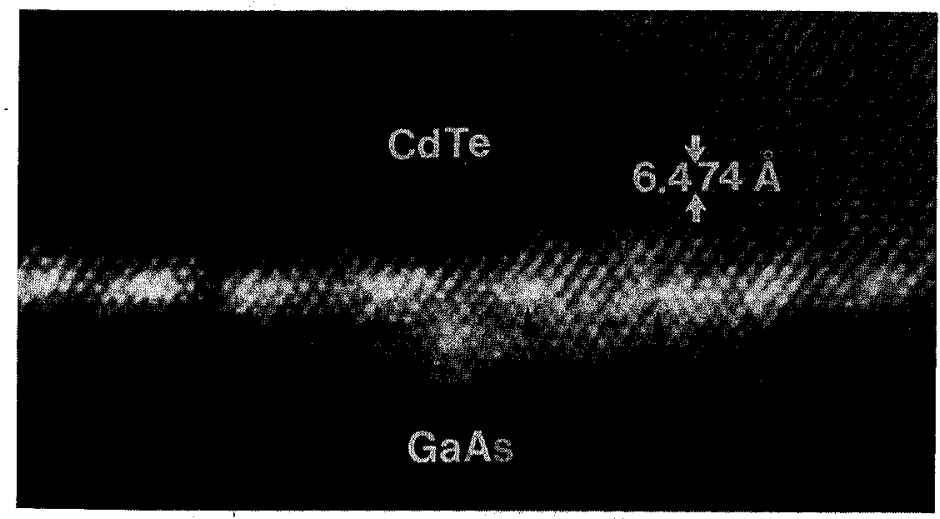

Fig. 8. A HRTEM micrograph of PLEE (001) $\mathrm{CdTe} /(001) \mathrm{GaAs}$ cross-section. The arrows indicate positions of misfit dislocations [23].

epitaxy is defined here as (001) CdTe/(001) GaAs and [110] CdTe/[110] GaAs with a $14.6 \%$ lattice mismatch occuring along two orthogonal $\langle 110\rangle$ directions in the interface plane. To accommodate such a significant lattice mismatch, misfit dislocations separated by about $3.2 \mathrm{~nm}$ are formed at the interface. The positions of these dislocations are indicated with the arrows. The picture indicates that an atomically sharp interface can be obtained in PLEE-grown films.

Optical properties of PLEE-grown layers were studied with low-temperature photoluminescence (PL) and Raman scattering. The data demonstrated that the epitaxial layers are of excellent quality which, in some cases, allowed us to observe unique features of CdTe. Comparison between the PL spectrum of a typical CdTe material used as target and that of a PLEE-grown (001) CdTe film on a (001) CdTe substrate [24] is provided in Fig. 9. Acceptor bound exciton lines at $1.589 \mathrm{eV}$ dominate both spectra. The free exciton and the exciton bound to a donor give rise to much weaker lines at 1.595 and $1.593 \mathrm{eV}$, respectively. A characteristic broad luminescence near $870 \mathrm{~nm}$ can be seen in the bulk material (Fig. 9(a)) but not in the film. The presence of this so-called "defect band" is believed to be due to $\mathrm{Cd}$ vacancies which are formed in high-temperature grown CdTe [25]. The high intensity and narrowness of the main PL peak at $1.589 \mathrm{eV}$ and the absence of the defect band indicate a high quality epitaxial film. Further evidence indicating the quality of the PLEE-grown material has been provided by Raman scattering experiments [26] which were carried out on (001) CdTe films grown on (001) GaAs. A-series of Raman spectra obtained with different laser excitation 
a

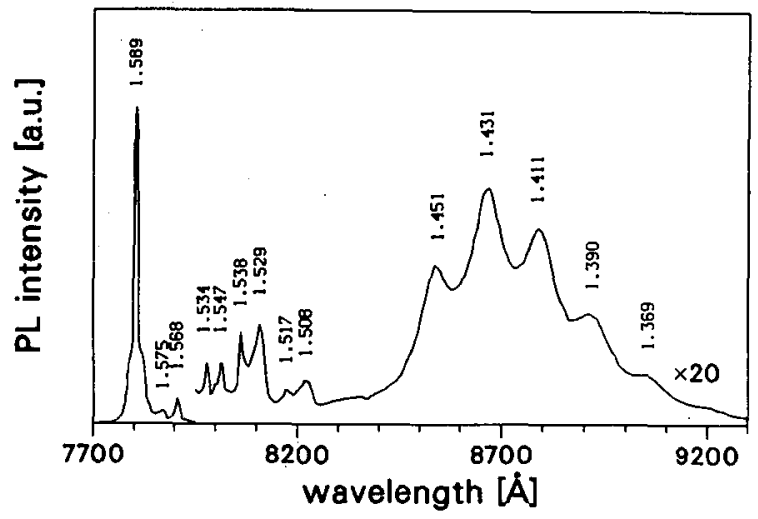

b

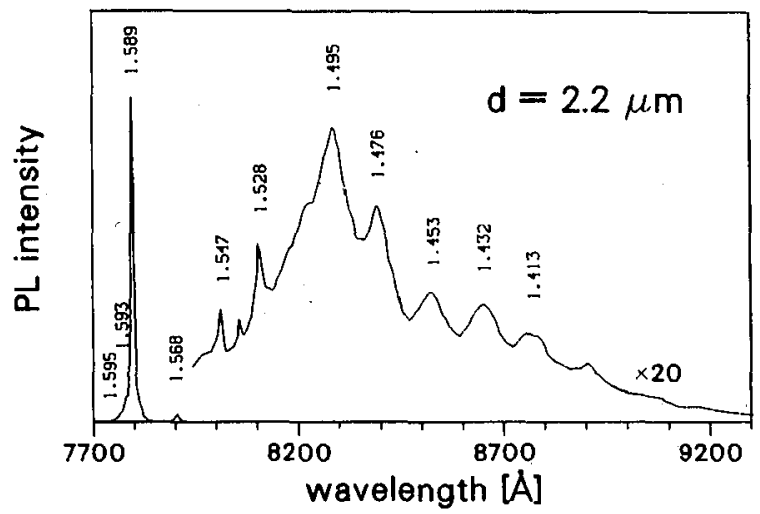

Fig. 9. A comparison between the PL spectrum of a bulk CdTe and that of a PLEE (001) CdTe film grown on (001). CdTe wafer [24].

energies, as shown in Fig. 10, demonstrate that with a higher excitation energy higher Raman resonances are observed. A maximum number of resonances was observed with a laser excitation energy $E_{\text {ex }}=2.66 \mathrm{eV}$. If the energy of an outgoing photon $E_{\text {ou }}$ is equal to any gap of a semiconductor a resonant Raman scattering occurs. In our case:

$$
E_{\text {ou }}=E_{\text {ex }}-n \hbar \omega_{\text {LO }} \approx E_{0}+\Delta_{0} \approx 2.54 \mathrm{eV} .
$$

For the CdTe phonon energy $\hbar \omega_{\mathrm{LO}}=20.1 \mathrm{meV}$ and $E_{\text {ex }}=2.66 \mathrm{eV}$ the above relation is fulfilled for $n=6$. This is the first time such high order Raman resonance has been observed in CdTe.

A comparison between the low-temperature PL and Raman spectra of PLEE-grown $\mathrm{Cd}_{1-x} \mathrm{Mn}_{x}$ Te films and bulk CdMnTe material has demonstrated that, as in the case of CdTe, the films have bulk-like characteristics. An illustration of this is shown in Fig. 11 where the PL spectrum of a bulk $\mathrm{Cd}_{0.90} \mathrm{Mn}_{0.10} \mathrm{Te}$ 

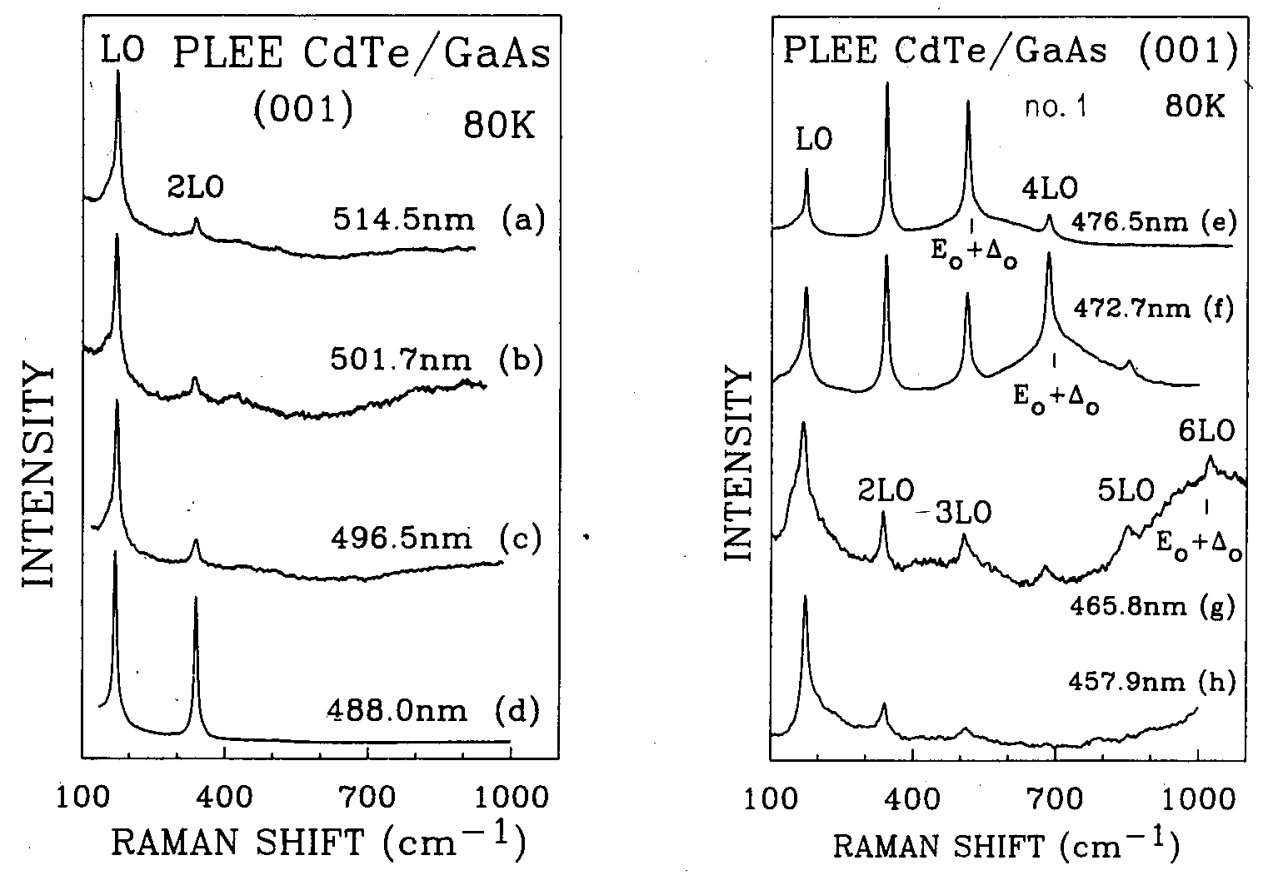

Fig. 10. Raman and resonant Raman spectra of a $1.62 \mu \mathrm{m}$ thick PLEE (001) CdTe film grown on (001) GaAs. 0utgoing resonant enhancement occurs with the PL emission near the $E_{0}+\Delta_{0}$ gap [26].

sample is compared with that of a $1.38 \mu \mathrm{m}$ thick PLEE (001) $\mathrm{Cd}_{0.896} \mathrm{Mn}_{0.104} \mathrm{Te}$ film grown on (001) InSb [27]. Both spectra are dominated by an acceptor related bound-exciton luminéscence near $1.74 \mathrm{eV}$. The corresponding peaks have full-width-at-half-maximum (FWHM) $\leq 10 \mathrm{meV}$ which is in good agreement with the theoretical value expected for samples with $x=0.10$. These results indicate that, in terms of crystallographic structure and chemical purity, the film corresponds to the best bulk material attainable. The resonant Raman scattering and PL experiments which were carried out $[5,28,29]$ for films with $0<x \leq 0.70$ demonstrate that the films are of high quality throughout the composition range. In particular, LO-phonon overtones higher than order $n=4$ have been observed for samples with high-range-Mn-concentration. Figure 12 shows the Raman spectrum for a PLEE $\mathrm{Cd}_{0.44} \mathrm{Mn}_{0.56} \mathrm{Te}$ sample [5]. The phonon replicas occur at multiples and combination of the "CdTe-like" $\mathrm{LO}_{1}$ and "MnTe-like" $\mathrm{LO}_{2}$ phonon frequencies up to eighth order. The overtones originate as outgoing resonant Raman scattering at an acceptor-related photoluminescence just below the fundamental gap $E_{0}\left(E_{0}+\Delta_{0}\right.$ in the case of CdTe, see Fig. 10). Again this is the first time such high-order overtones have been observed in any $\mathrm{Cd}_{1-x} \mathrm{Mn}_{x} \mathrm{Te}$. 


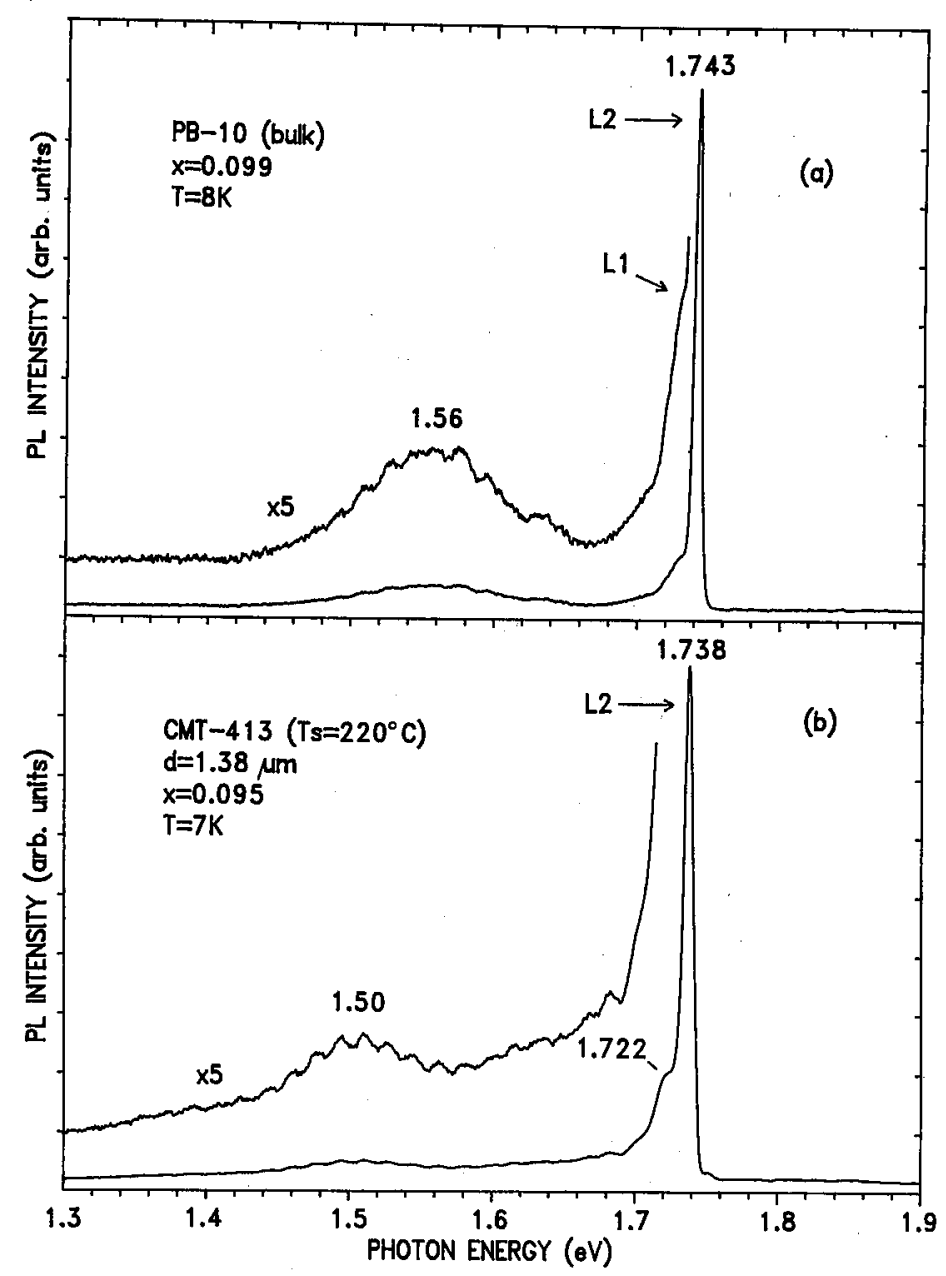

Fig. 11. A comparison between the PL spectrum of (a) bulk $\mathrm{Cd}_{0.90} \mathrm{Mn}_{0.10} \mathrm{Te}$ and (b) that of a PLEE (001) $\mathrm{Cd}_{0.896} \mathrm{Mn}_{0.104} \mathrm{Te}$ film grown on (001) InSb wafer [27].

\subsection{Quantum wells and superlattices}

Computer controlled operation of lasers used in PLEE allowed the instantaneous switching of the vaporization of CdTe and $\mathrm{Cd}_{1-x} \mathrm{Mn}_{x} \mathrm{Te}$ targets. With such an approach we have grown multiple quantum well and superlattice structures with periods from 81 to $492 \AA$. An example of a PLEE-grown multiple quantum well structure [6] is illustrated in Fig. 13. In this figure, a secondary-ion-mass-spectroscopy (SIMS) profile of $\mathrm{Mn}, \mathrm{Cd}$ and $\mathrm{Zn}$ for a 30 period structure of (001) CdTe$-\mathrm{Cd}_{1-x} \mathrm{Mn}_{x} \mathrm{Te}$ grown on (001) $\mathrm{Cd}_{0.95} \mathrm{Zn}_{0.05} \mathrm{Te}$ is shown. It can be seen that within the depth resolution of the SIMS measurement, typically $\sim 30 \AA$, a very uniform structure has been produced. A reduced amplitude of the $\mathrm{Mn}$ and $\mathrm{Cd}$ sig- 


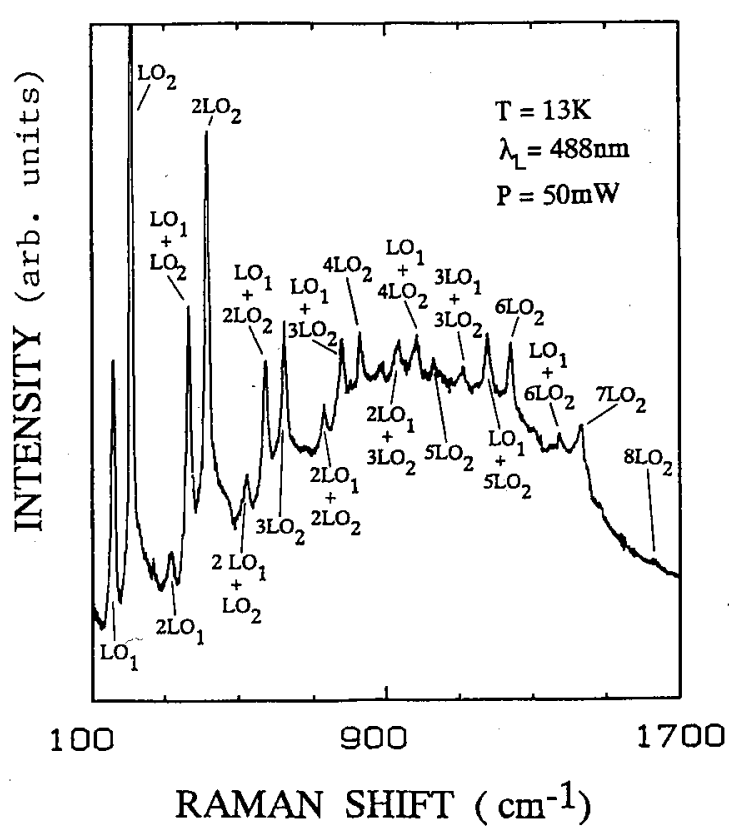

Fig. 12. Raman spectrum of à $0.9 \mu \mathrm{m}$ thick PLEE (111) $\mathrm{Cd}_{0.44} \mathrm{Mn}_{0.56}$ Te film grown on (111) GaAs. Outgoing resonant enhancement occurs with the PL emission near the $E_{0}$ gap [5].

nals near the interface is most likely due to the SIMS memory effect. Structural and optical quality of the superlattices was examined with double crystal X-ray diffraction (DCXD) [6] and low-temperature photoluminescence excitation (PLE) studies [30]. A typical DCXD rocking curve consisted of the substrate peak, the main superlattice peak, and the satellite superlattice peaks up to the third order. Numerical calculation revealed [6] that the layers become completely relaxed as the superlattice period increases from $\sim 190$ to $490 \AA$.

Typical low-temperature PL and PLE spectra observed for the PLEE CdTe$-\mathrm{Cd}_{1-x} \mathrm{Mn}_{x}$ Te superlattices are shown in Fig. 14. The nature of the different peaks which appear in the PL spectrum has been determined with the help of the PLE data. For the clarity of the figure only the excitation spectrum of the $X$ line is indicated. The first line $X_{h h}$ in the PLE spectrum is related to the free $E_{1}-H H_{1}$ exciton recombination. The small shift between $X$ and $X_{h h}$ allows the identification of $X$ as a weakly bound $E_{1}-H H_{1}$ excitonic recombination, the other lines in the PL spectrum are impurity related. Two features of these spectra allow us to discuss the quality of the sample: first, the energy difference between $X$ and $X_{h h}$, the so-called Stokes shift (SS), and secondly, the FWHM of the PL line. The Stokes shift is due to the trapping of the free exciton on interface defects [31]. A large Stokes shift indicates very rough interfaces. The experimental values of the Stokes shifts for different samples are reported in Table III. These values are 


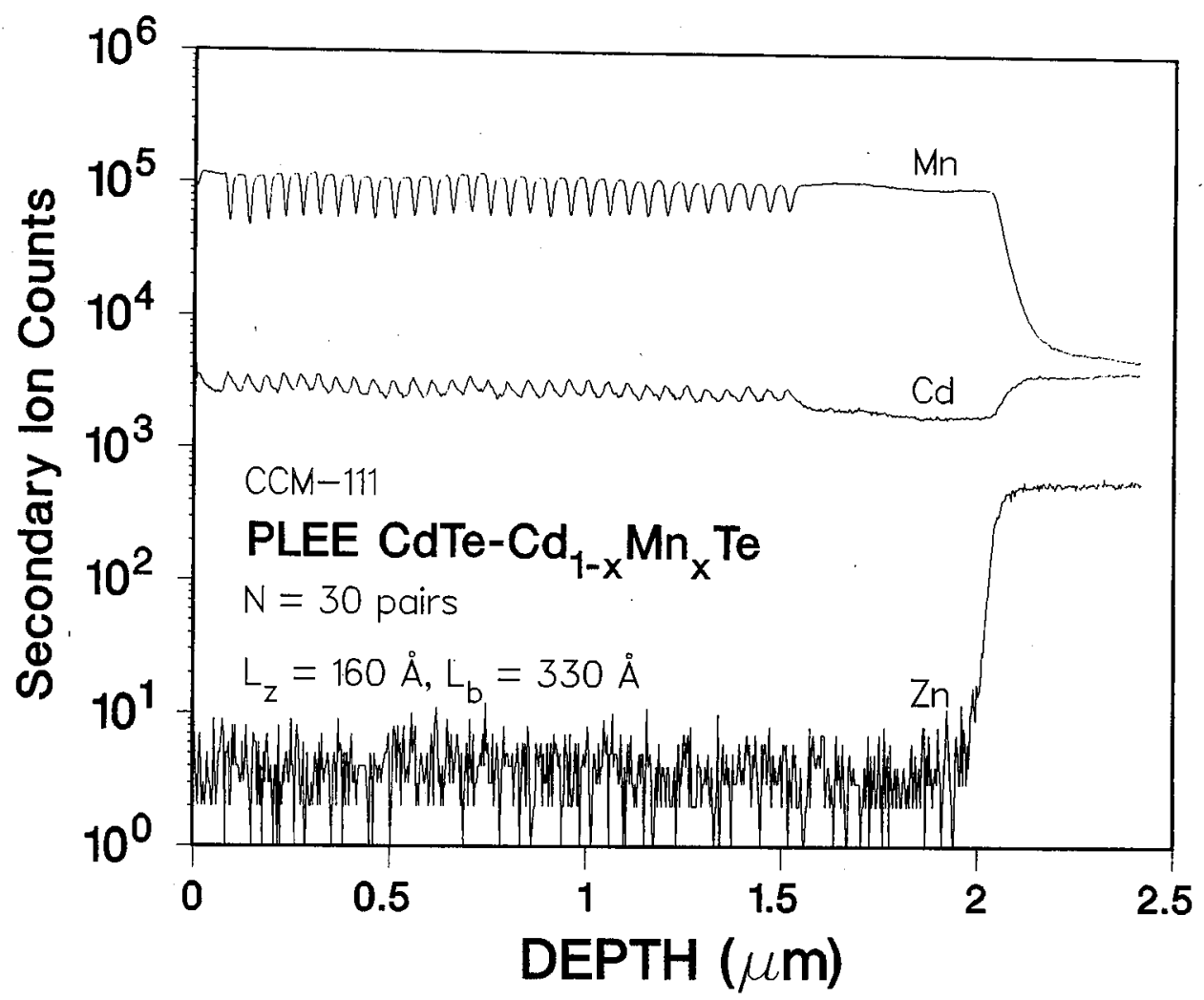

Fig. 13. Typical SIMS in-depth $\mathrm{Mn}, \mathrm{Cd}$ and $\mathrm{Zn}$ profiles of a PLEE (001) $\mathrm{CdTe}-\mathrm{Cd}_{0.90} \mathrm{Mn}_{0.10} \mathrm{Te}$ multiple quantum well structure grown on (001) $\mathrm{Cd}_{0.95} \mathrm{Zn}_{0.05} \mathrm{Te}$ wafer [6].

comparable to, and for several samples (CCM-102, 108, 110 and 111) even smaller than those obtained in MBE-grown samples [32, 33]. The width of the PL lines is attributed to well-width fluctuations in different wells of the superlattice and to well-width variation in a given well. This leads to a dispersion of the confinement energies of the hole and electron states, thus to a dispersion of the excitonic recombination energy. The experimental values of the FWHM of the $X$ line for the different samples are reported in the Table IV. The FWHM is distributed around a mean value of $8 \mathrm{meV}$, which is comparable to the values obtained in MBE samples [32-34]. These two observations allow us to conclude that the quality of the samples is comparable to the quality of the best currently available samples [35]. 


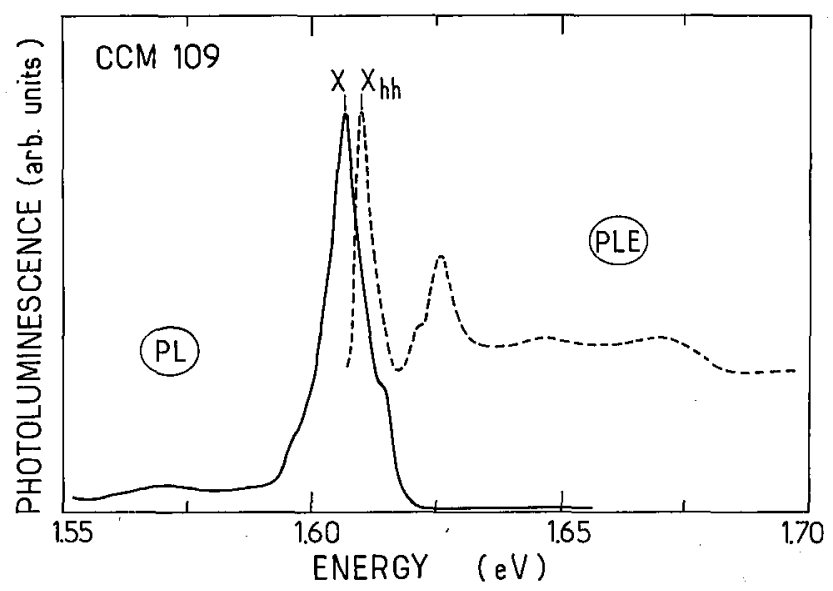

Fig. 14. Low-temperature photoluminescence (solid line) and photoluminescence excitation (broken line) data for a PLEE-grown structure consisting of 22 pairs of (001) $\mathrm{CdTe}-\mathrm{Cd}_{0.90} \mathrm{Mn}_{0.10} \mathrm{Te}$ on (001) $\mathrm{Cd}_{0.95} \mathrm{Zn}_{0.05} \mathrm{Te}$ wafer [30].

TABLE III

Properties of PLEE (001)Cd $\mathrm{Cd}_{1-x} \mathrm{Mn}_{x}$ Te layers grown on (001)InSb substrates. Composition of the laser ablated target was $x=0.07$. No additional flux of Cd was applied [11].

\begin{tabular}{c|c|c|c|c|c}
\hline \hline Sample & $T_{\mathrm{S}}$ & $d$ & \multicolumn{2}{|c|}{$X$} & PL \\
\cline { 4 - 5 } & $\left({ }^{\circ} \mathrm{C}\right)$ & $(\mu \mathrm{m})$ & EDAM \\
& & 1.0 & 0.096 & 0.097 & 16 \\
\hline CMT-414 & 200 & & & \\
CMT-401 & 210 & 2.15 & 0.106 & 0.109 & 9 \\
CMT-412 & 210 & 1.45 & 0.109 & 0.108 & 11 \\
CMT-409 & 220 & 1.05 & 0.102 & 0.096 & 13 \\
CMT-413 & 220 & 1.38 & 0.104 & 0.096 & 10 \\
CMT-410 & 225 & 1.67 & 0.101 & 0.094 & 12 \\
CMT-415 & 230 & 1.0 & 0.106 & 0.116 & 12 \\
CMT-418 & 240 & 1.0 & 0.114 & 0.124 & 20
\end{tabular}


TABLE IV Structural properties of $\operatorname{PLEE}(001) \mathrm{CdTe}-\mathrm{Cd}_{1-x} \mathrm{Mn}_{x} \mathrm{Te}(x=0.10)$ multiple quantum well and superlattice structures grown on (001) $\mathrm{Cd}_{0.955} \mathrm{Zn}_{0.045} \mathrm{Te}$ substrates (except the sample CCM-101) [30].

\begin{tabular}{c|c|c|c|c|c|c|c}
\hline \multirow{2}{*}{ Sample } & $\begin{array}{c}N \\
\text { pairs }\end{array}$ & \multicolumn{2}{|c|}{$\begin{array}{c}\text { SL period } \\
(\AA)\end{array}$} & \multicolumn{2}{c|}{$\begin{array}{c}d_{\mathrm{w}} \\
(\AA)\end{array}$} & PL $_{F W H M}$ & $\begin{array}{c}\text { Stokes } \\
\text { shift } \\
(\mathrm{meV})\end{array}$ \\
\cline { 3 - 6 } & & SIMS & DCXD & SIMS & OPT & $(\mathrm{meV})$ & 7.8 \\
\hline CCM-101 $^{\mathrm{a}}$ & 20 & 355 & - & 213 & 260 & 7.5 & $\mathbf{5 . 8}$ \\
CCM-102 & 49 & $81^{\mathrm{b}}$ & - & $54^{\mathrm{b}}$ & 63 & 7.0 & 3.3 \\
CCM-108 & 30 & 290 & 363 & 120 & 130 & 5.5 & 3.4 \\
CCM-109 & 22 & 313 & 404 & 88 & 119 & 8 & 2.9 \\
CCM-110 & 15 & 187 & 214 & 140 & 151 & 6.2 & 3.6 \\
CCM-111 & 30 & 490 & - & 160 & 160 & 8.6 & 5.3 \\
CCM-112 & 44 & 492 & 592 & 245 & 260 & 9.5 & 5.4 \\
CCM-114 & 22 & 348 & 428 & 159 & 181 & 9.5 &
\end{tabular}

Grown on (001) InSb substrate.

b From TEM results.

\subsection{Band-gap engineering}

The use of lasers for sequential or simultaneous ablation of two different targets allowed us to produce ternary semiconductors with a gradient of composition which could be arbitrarily defined. An example of such a structure is shown in Fig. 15. In this case, $\mathrm{CdTe}$ and $\mathrm{Cd}_{1-x} \mathrm{Mn}_{x} \mathrm{Te}(x=0.56)$ targets were ablated with $\mathrm{Nd}$ :YAG laser triggered at $500 \mathrm{~Hz}$ and excimer $\mathrm{XeCl}$ laser triggered at frequency $\leq 60 \mathrm{~Hz}$. A series of $\mathrm{Cd}_{1-x} \mathrm{Mn}_{x} \mathrm{Te}(50 \AA)-\mathrm{CdTe}(50 \AA)$ layers was grown first and then a $\mathrm{Cd}_{1-x} \mathrm{Mn}_{x} \mathrm{Te}$ structure with a gradient of chemical composition from $x \approx 0.30$ to $x=0$ was formed over the thickness of about $700 \AA$. This was achieved by maintaining a constant deposition rate of $\mathrm{CdTe}$ while vaporization of the $\mathrm{Cd}_{1-x} \mathrm{Mn}_{x} \mathrm{Te}$ target was gradually phased out as the triggering of the $\mathrm{XeCl}$ laser was reduced from 60 to $0 \mathrm{~Hz}$.

Another example of a complex PLEE-grown structure is shown in Fig. 16 [36]. It consists of two series of $\mathrm{Cd}_{0.89} \mathrm{Mn}_{0.11} \mathrm{Te}-\mathrm{CdTe}$ pairs grown between a 0.46 $\mu \mathrm{m}$ thick buffer layer and a $0.11 \mu \mathrm{m}$ thick cap layer. The thickness of CdTe layers was kept equal to $105 \AA$ whereas the thickness of $\mathrm{Cd}_{0.89} \mathrm{Mn}_{0.11}$ Te layers was $250 \AA$ and $125 \AA$ in the first and the second series grown respectively. It can be seen that within the resolution of SIMS measurements good control and reproducibility of the film thickness is achieved. Preliminary TEM results confirmed the SIMS findings. A cross-section TEM micrograph showing the interface region between the two series of $\mathrm{Cd}_{0.89} \mathrm{Mn}_{0.11} \mathrm{Te}-\mathrm{CdTe}$ layers described above is shown in Fig. 17 . A well-preserved periodicity is clearly seen and the estimated widths of individual layers remain in reasonable agreement with the widths intended in the growth process. We would like to point out that these results were obtained with lasers as the only heat sources employed for the generation of suitable atom/molecule fluxes and no effusion cells, typical of the laser-MBE approach [3] were applied. 


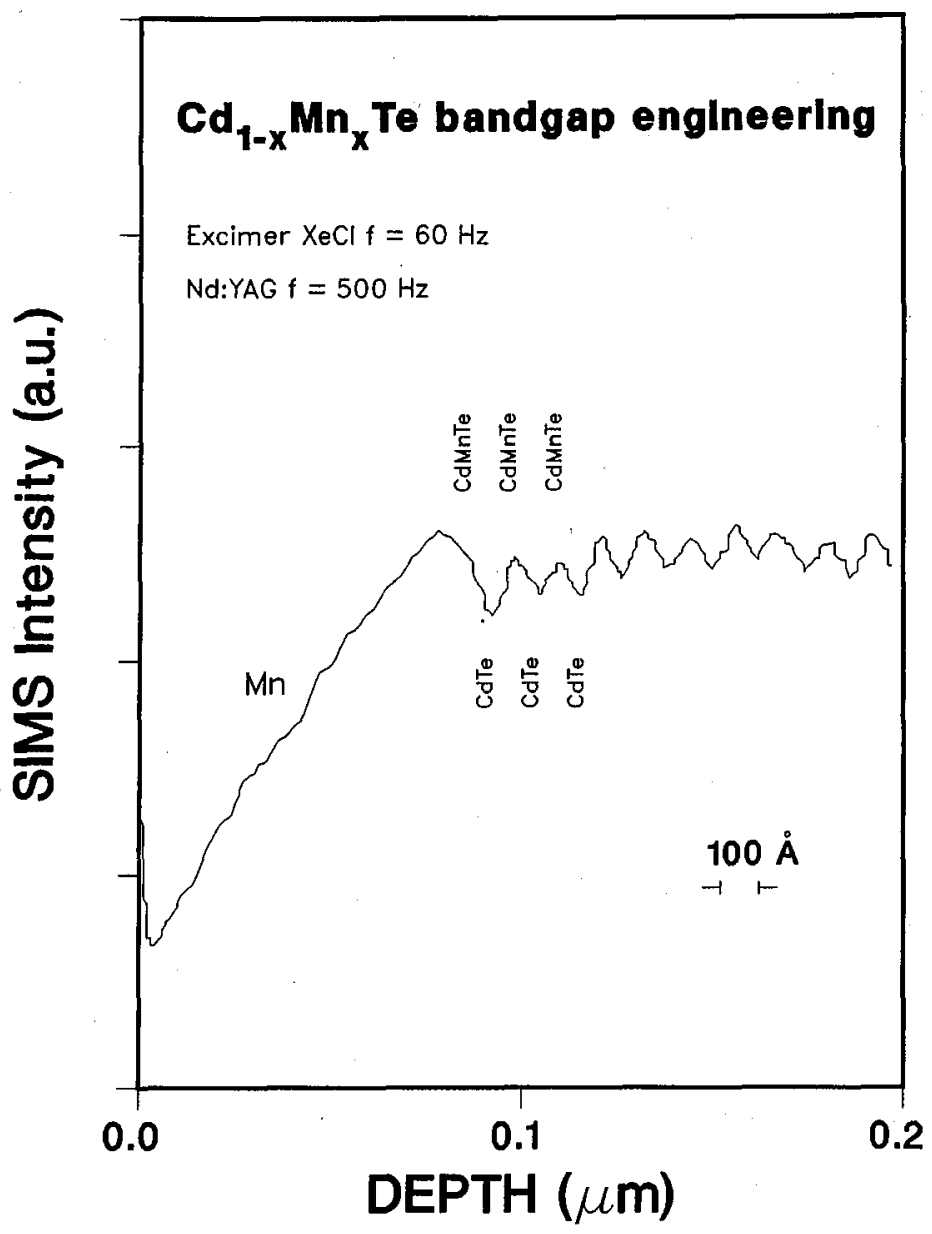

Fig. 15. SIMS Mn profile of a PLEE-grown CdTe-Cd ${ }_{1-x} \mathrm{Mn}_{x}$ Te structure with an intentionally created gradient of chemical composition near the surface.

\section{Conclusions}

In this review, we have discussed basic problems related to the application of pulsed lasers for the evaporation and epitaxial growth of multi-element semiconductors. Phenomena that are critical in Pulsed Laser Evaporation and Epitaxy like threshold for ablation, geometrical and chemical changes of targets and properties of laser induced vapours have also been reviewed. A PLEE system with computer control features has been outlined. Structural and optical properties of PLEE-grown material have been discussed, mostly with respect to CdTe and $\mathrm{Cd}_{1-x} \mathrm{Mn}_{x} \mathrm{Te}$. Properties of $\mathrm{Cd}_{1-x} \mathrm{Mn}_{x}$ Te films and CdTe-Cd $\mathrm{d}_{1-x} \mathrm{Mn}_{x} \mathrm{Te}$ multilayer quantum wells and superlattices grown with PLEE have been described. The re- 


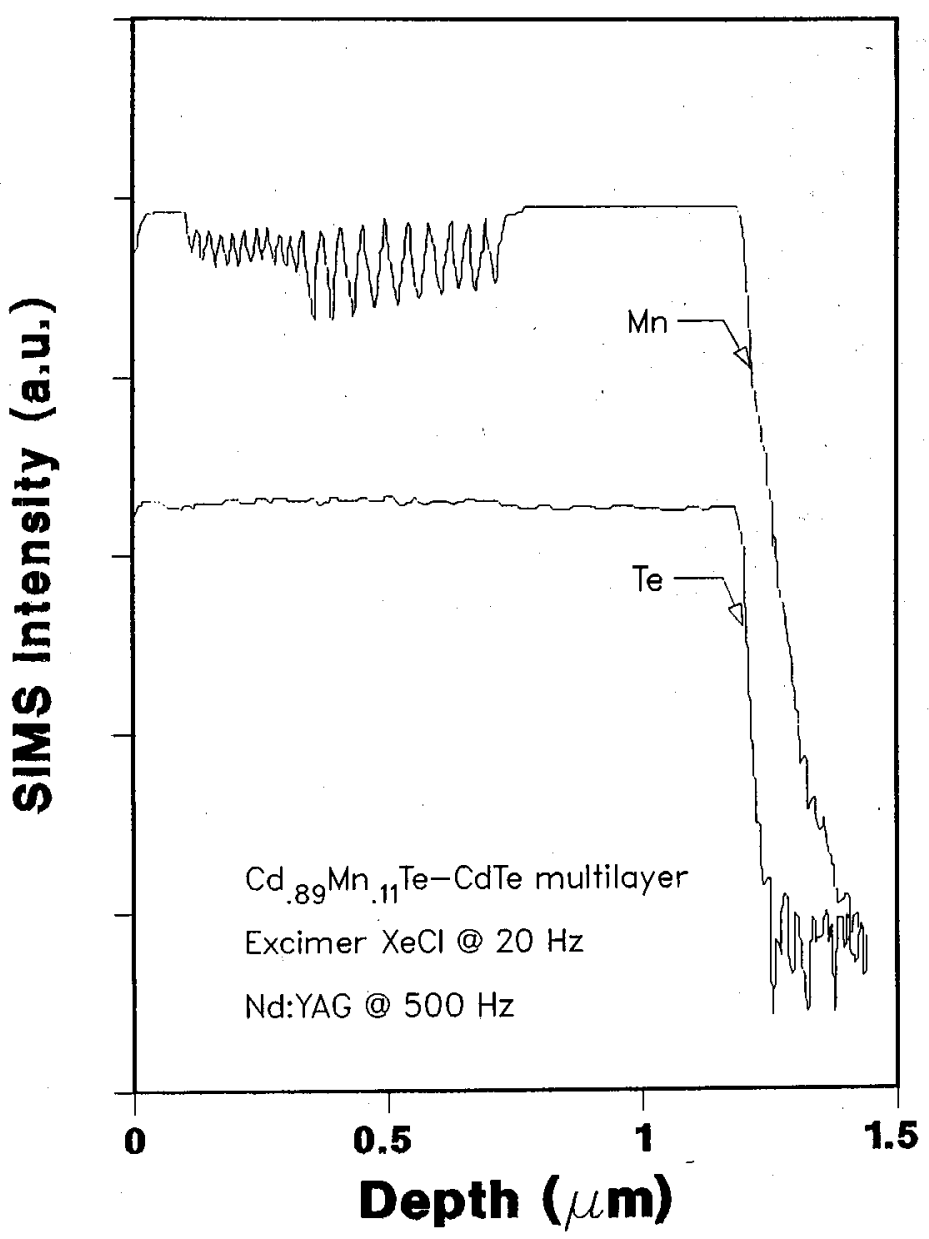

Fig. 16: SIMS profiles of $\mathrm{Mn}$ and $\mathrm{Te}$ in a PLEE-grown structure of $\mathrm{Cd}_{0.89} \mathrm{Mn}_{0.11} \mathrm{Te}-\mathrm{CdTe}$. The thickness of a CdTe layer is $105 \AA$ and that of a CdMnTe layer is $250 \AA$ and $125 \AA$ in the first and second series of pairs respectively [36].

sults produced thus far indicate that excellent quality material can be grown. In most cases, it was possible to compare the PLEE-grown samples favourably to those grown by other methods, e.g. Molecular Beam Epitaxy. Some basic features of $\mathrm{CdTe}$ and $\mathrm{Cd}_{1-x} \mathrm{Mn}_{x} \mathrm{Te}$ were observed for the first time due to the quality of the PLEE-grown samples.

The ultra-pure vacuum that can be maintained during laser ablation and an ability to carry out congruent vaporization of complex targets alone are sufficient features to justify a steadily growing interest in this technique. Moreover, taking into account that a PLEE system can be easily adapted for the deposition of different materials (changing a target in the system is as easy as changing the 


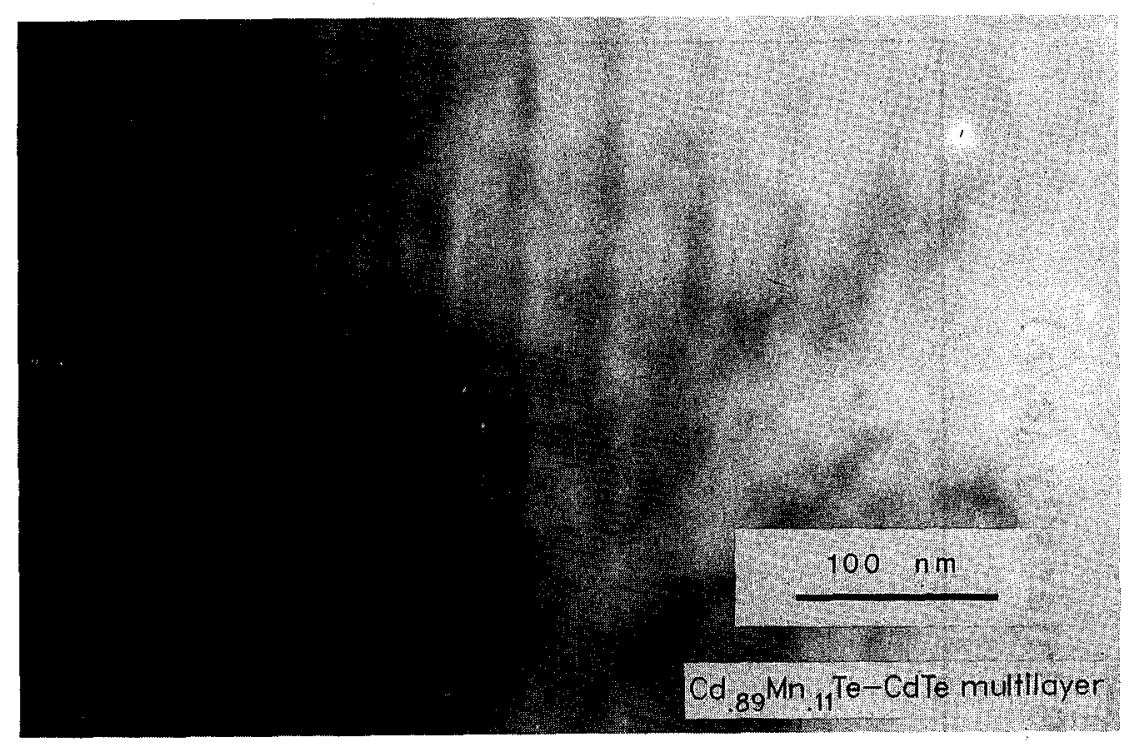

Fig. 17. Transmission electron microscope micrograph showing the interface region between the two series of layers from Fig. 17 [36].

substrate) it has to be regarded as an important step in the development of systems for thin film deposition and epitaxy.

\section{Acknowledgement}

The author would like to express his gratitude to D.F. Williams who contributed greatly to the subject of PLEE, especially at the early stage of its development at the NRC. Contribution of the co-authors of the cited papers and the stimulating atmosphere in the Advanced Epitaxy Section are also acknowledged.

\section{References}

[1] J.F. Ready, Effects of High-Power Laser Radiation, Academic Press, New York 1971.

[2] J.J. Dubowski, Chemtronics 3, 66 (1988).

[3] J.T. Cheung, H. Sankur, Critical Rev. Solid St. Mater. Sci. 15, 63 (1988).

[4] D.C. Paine, J.C. Bravman (Eds.), "Laser Ablation for Materials Synthesis", Mater. Res. Soc. Symp. Proc., Vol. 191 (1990).

[5] W.J. Keeler, H. Huang, J.J. Dubowski, Phys. Rev. B 42, 11355 (1990).

[6] J.J. Dubowski, A.P. Roth, Z.R. Wasilewski, S.J. Rolfe, Appl. Phys. Lett., in press.

[7] R.K. Singh, J. Narayan, Phys. Rev. B 41, 8843 (1990). 
[8] J.R. Thompson, M.Sc. thesis, University of Waterloo, 1990.

[9] J.M. Wrobel, J.J. Dubowski, Appl. Phys. Lett. 55, 469 (1989).

[10] J.J. Dubowski, J. Cryst. Growth 101, 105 (1990).

[11] J.J. Dubowski, J.R. Thompson, R. Benzaquen, A.P. Roth, Z. Wasilewski, Can. J. Phys. 69, 270 (1991).

[12] M. Hanabusa, S. Moriyama, H. Kikuchi, Thin Solid Films 107, 227 (1983).

[13] S.R. Foltyn, R.E. Muenchausen, R.C. Estler, E. Peterson, W.B. Hutchinson, K.C. Ott, N.S. Nogar, K.M. Hubbard, in Ref. [4], p. 205.

[14] J.J. Dubowski, P.K. Bhat, D.F. Williams, P. Becla, J. Vac. Sci. Technol. A 4, 1879 (1986)

[15] P.D. Brewer, J.J. Zink, G.L. Olsen, in Ref. [4], p. 67.

[16] A.D. Akhsakhalyan, Yu.A. Bityurin, S.V. Gaponov, A.A. Gudkov, V.I. Luchin, Sov. Phys. Tech. Phys. 27, 969 (1982); in Russian: Zh. Tekh. Fiz. 52, 1584 (1982).

[17] S.V. Gaponov, V.H. Genkin, A.A. Gudkov, M.Yu. Myl'nikov, Sov. Phys. Tech. Phys. 27, 822 (1982); in Russian: Zh. Tekh. Fiz. 52, 1351 (1982).

[18] S.V. Gaponov, A.A. Gudkov, B.M. Luskin, V.I. Luchin, N.N. Salashchenko, Sov. Phys. Tekh. Fiz. 26, 598 (1981); in Russian Zh. Tekh. Fiz. 51, 1000 (1981).

[19] S.V. Gaponov, A.A. Gudkov, A.A. Fraerman, Sov. Phys. Tech. Phys. 27, 1130 (1982); in Russian: Zh. Tekh. Fiz. 52, 1843 (1982).

[20] D. Lubben, S.A. Barnett, K. Suzuki, S. Gorbatkin, J.E. Greene, J. Vac. Sci. Technol. B 3, 968 (1985).

[21] J.J. Dubowski, D.F. Williams, J.M. Wrobel, P.B. Sewell, J. LeGeyt, C. Halpin, D. Todd, Can. J. Phys. 67, 343 (1989).

[22] R.D. Feldman, D.W. Kisker, R.F. Austin, K.S. Jeffers, P.M. Bridenbaugh, J. Vac. Sci. Technol. A 4, 2234 (1986).

[23] J.H. Mazur, unpublished results.

[24] J.M. Wrobel, J.J. Dubowski, P. Beclà, J. Vac. Sci. Technol. A 7, 338 (1989).

[25] T. Taguchi, J. Shirafuji, Y. Inuishi, Rev. Phys. Appl. 12, 117 (1977).

[26] Z.C. Feng, S. Perkowitz, J.M. Wrobel, J.J. Dubowski, Phys. Rev. B 39, 12997 (1989).

[27] C. Qiu, M.Sc. thesis, Dalhousie University, 1990.

[28] Z.C. Feng, S. Perkowitz, J.J. Dubowski, J. Appl. Phys. 69, 7782 (1991).

[29] W.J. Keeler, J.J. Dubowski, Can. J. Phys. 69, 255, (1991).

[30] J.J. Dubowski et al., to be published in J. Cryst. Growth.

[31] G. Bastard, C. Delalande, M.H. Meynadier, P.M. Frijlink, M. Voos, Phys. Rev. B 29, 7042 (1984).

[32] L. Vina, L.L. Chang J., Yoshino, J. Phys. 48, C5-317 (1987).

[33] X.C. Zhang, S.K. Chang, A.V. Nurmikko, L.A. Kolodziejski, R.L. Gunshor, S. Datta, Phys. Rev. B 31, 4056 (1985).

[34] E. Deleporte, J.M. Berroir, G. Bastard, C. Delalande, J.M. Hong, L.L. Chang, Phys. Rev. B 42, 5891 (1990). 
[35] A. Wasiela, Y. Merle d'Aubigné, J.E. Nicholls, D.E. Ashenford, B. Lunn, Solid State Commun. 76, 263 (1990).

[36] J.J. Dubowski, J.R. Thompson, S.J. Rolfe, J.P. McCaffrey, Superlattices Microstruct. 9, 327 (1991). 